\title{
EVA London 2021: Keynote summaries
}

\author{
Jonathan P. Bowen \\ London South Bank University \\ London, UK \\ (editor) \\ http://www.jpbowen.com \\ jonathan.bowen@lsbu.ac.uk
}

\author{
Ernest Edmonds \\ De Montfort University \\ Leicester, UK \\ http://www.ernestedmonds.com \\ ernest@ernestedmonds.com
}

\author{
Camille Baker \\ University for the Creative Arts \\ Farnham, Surrey, UK \\ https://www.uca.ac.uk/staff- \\ profiles/prof-camille-baker \\ cbaker10@uca.ac.uk
}

\author{
Ghislaine Boddington \\ University of Greenwich \\ London, UK \\ https://www.gre.ac.uk/people/rep/la \\ s/ghislaine-boddington \\ s.g.boddington@greenwich.ac.uk
}

\begin{abstract}
This paper includes summaries of keynote presentations and short biographies of the keynote speakers at the EVA London 2021 Conference on Electronic Visualisation and the Arts. The talks were delivered online due to the Covid-19 pandemic. EVA London broadly covers the digital arts and humanities, attracting a wide set of interdisciplinary participants. The keynote speakers, while largely affiliated with academic institutions, have wider interests as well.
\end{abstract}

Art and technology. Digital art. Digital culture. Digital intimacy. Digital preservation. Non-Fungible Tokens (NFTs).

\section{INTRODUCTION}

This paper records summaries of invited keynote talks and backgrounds of the keynote speakers at the EVA London 2021 Conference (Weinel et al. 2021). EVA London takes place annually, originally starting in 1990 (Bowen 2020; Hemsley 2013). As for the previous year, due to the Covid-19 pandemic, EVA London 2021 is a completely online conference. The conference is broadly based on digital culture (Giannini \& Bowen 2019b; Bowen \& Giannini 2021) with a special emphasis on digital art (Bowen 2013). The conference also includes a symposium panel with three invited panellists presenting position statements (Bowen et al. 2021).

\section{SUMMARIES}

\section{Merel van Helsdingen \\ Nxt Museum, Netherlands}

\section{The Rise of the NFT Market}

This talk covers the rise of the Non-Fungible Token (NFT) market for digital art, giving a brief history and explanation of what it is and where we stand at this point, followed by a more in-depth discussion about the impact on artists and institutions. The talk addresses the positives and opportunities, but also the negatives and potential threats.

\section{Biography}

Merel van Helsdingen is the founder and managing director at Nxt Museum (http://nxtmuseum.com), the first museum in the Netherlands dedicated to new media art, based in Amsterdam. Merel has worked on marketing and partnerships for tech, music, and entertainment companies in London (Apple, BBH, Crowdmix). She specialised in digital marketing and entertainment partnerships at $\mathrm{BBH}$, working with the likes of Rovio, Disney, YouTube, and Universal Music.

Merel's passion for new media, film, and music, combined with her entrepreneurial flair, inspired the idea for Nxt Museum in 2018. Over the last two and a half years, Merel has built the museum from scratch, leading on everything from the concept to fundraising and artist liaison, with the support of her network of advisors. She holds a Bachelor's degree in Media \& Culture and a Master's degree in Marketing. 


\section{Terrence Masson}

School of Visual Arts, USA

\section{Preservation of Digital Culture}

Historical knowledge is of course critically important in every field, none perhaps more so than the arts. Classical art history does not have a formal analogy in modern digital culture to the extent that we still have living founders of our industry. Imagine practitioners in modern aeronautics being able to talk to and collaborate with Orville and Wilbur Wright. Our privilege now and our responsibility is to take advantage of our elder colleagues' stories, to talk about their personal experiences and share these wonderful first-person perspectives with the world. "The People Behind the Pixels" (see Figures 1 and 2) has been and continues to be an attempt to actively collect, connect and visualise this modern digital culture as an ever-growing resource to benefit students, teachers, and practitioners.

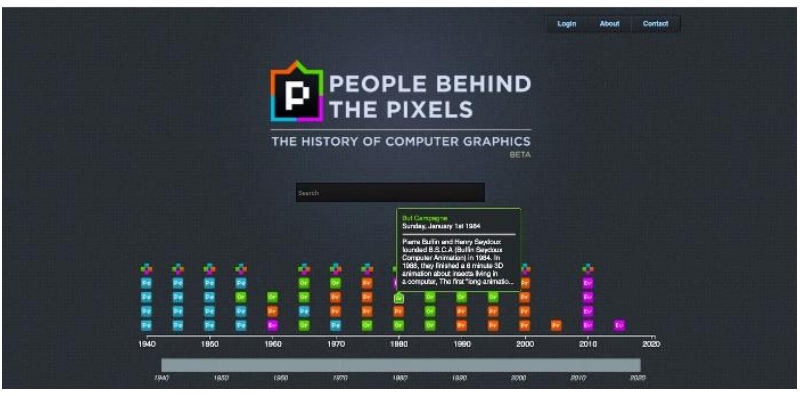

Figure 1: People Behind the Pixels: The History of Computer Graphics (http://www. historyofcg.com).

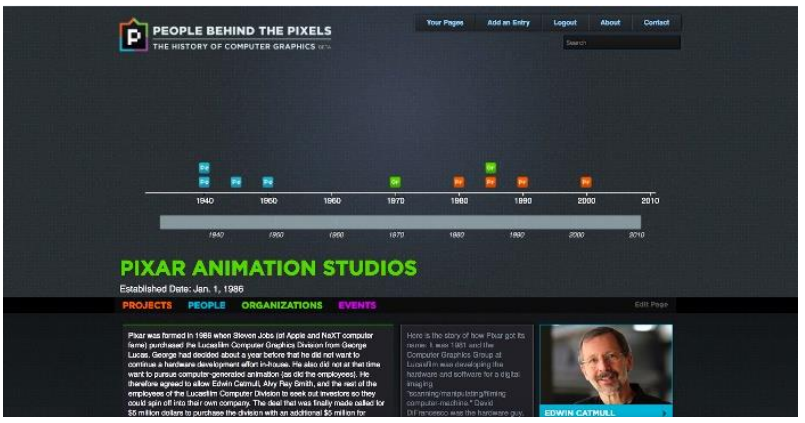

Figure 2: Pixar Animation Studios.

\section{Biography}

Terrence Masson is an educator and computer graphics historian with 30 years of production and education leadership experience. As an animation and visual effects artist/producer, his work includes live-action visual effects, animated feature and short animated films, VR/AR, video games and theme park special venues. Prior to joining the School of Visual Arts as Chair of the MFA Computer Arts department in 2016, he founded and served as CEO of a location-based mobile augmented reality company called Building
Conversation to serve on-site architectural visualisation. His book CG101: A Computer Graphics Industry Reference (Masson 2007) is a standard text worldwide for both studio executives and students.

Terrence came up through the ranks on more than 20 feature films including Hook, True Lies, Interview with the Vampire and three Star Wars movies; along with supervising numerous interactive projects such as SimCity4, Bruce Lee, Batman Dark Tomorrow and Alter Echo. He developed the original CG animation method for SouthPark in 1996 and his short film Bunkie \& Booboo won first place in the World Animation Celebration in 1998. An active volunteer with SIGGRAPH since 1988, Terrence served as 2006 Computer Animation Festival Chair, SIGGRAPH 2010 Conference Chair and ACM SIGGRAPH Outstanding Service Awards Chair. Terrence is a member of the Producers Guild of America, the Visual Effects Society and a past ACM Distinguished Lecturer. He has been involved with the international FMX Conference on Animation, Effects, Games and Immersive Media since 1999 and the View international computer graphics conference on Animation VFX Games VR/AR since 2010.

\section{Camille Baker}

University for the Creative Arts, UK

\section{S+T+ARTS:EU DG-CNT Arts \& Technology Innovation Initiative: 2012-present}

The Science, Technology, and the Arts initiative of the Digital Single Market (STARTS) is the result of several activities under the umbrella of ICT ART CONNECT. It all started in April 2012, at the first homonymous event compromising a large gathering of people working on European Union (EU) funded projects that in different ways included the arts. The main meeting took place at the EU Berlaymont building in Brussels, which included an exhibition in a local gallery and workshops at the iMAL Art Center for Digital Cultures and Technology, in Molenbeek, Belgium. Many people were mobilised to develop the initial ideas for the first event, that in turn led to the first small EU Coordination and Support Action (CSA) that was funded to further mobilise around these ideas. This first project was funded under the Future and Emerging Technologies framework, and originally titled FET-ART.

2013 was a key year for the growth of ICT ART CONNECT. Taking advantage of the then ongoing restructuring period of transition from Framework Programme 7 (FP7) to Horizon 2020 (H2020), directly after EU showcase event ICT 2013 in Vilnius. Then an event took place in Brussels that 
radically boosted synergies around potential EU policies on the integration of artists in the then forthcoming H2020 framework. Because of these efforts put in place in 2013 by the activities of FETArt, the first H2020 topic and subsequent consortium project dedicated to STARTS was funded. It was titled ICT-36-2016 - FET-ART: Boost synergies between artists, creative people and technologists, then renamed ICT \& Art Connect: Boost synergies between artists, creative people and technologists. That H2020 topic then followed onto support the next projects: STARTS $P R I Z E$, managing the award of prizes to the STARTS community, VERTIGO, coordinating STARTS in general and implementing the first STARTS Residencies and WEAR SUSTAIN, promoting ethical and sustainable wearable and etextile design ideas resulting from arts and engineering collaborations. BRAINHACK, a FET funded project about community building around brain-computer interfaces, and the one-off Creative Europe funded STARTS Prize covered the transition in terms of activities between the end of the ICTARTCONNECT.study and the start of ICT36-2016 funded projects. This has since been followed by six more funded projects currently underway or finishing in 2021:

- $\quad$ STARTS Ecosystem (April 2019 - November 2021)

- Lighthouse pilots (http://www.starts.eu/lighthouses):

o RE-Fream (December 2018 - November 2021)

- MINDSpaces (January 2019 - December 2021)

- Digital Innovation Hubs (http://www.starts.eu/digitalinnovation-hubs):
- Better Factory (October 2020 - September 2024)

- MediaFutures (September 2020 - August 2023)

- VOJEXT (July 2020 - December 2023)

This is not to mention the Regional STARTS Centres around Europe and STARTS Academies (http://www.starts.eu/academies), all developing in different ways the STARTS agenda and more to be funded under Horizon Europe with calls opening in March this year.

I have played a key role in the evolution and impact of the European Commission's DG-Connect initiative: STARTS (Science Technology + Arts). Through its EU funded consortium projects and activities, STARTS has impacted European innovation and ingenuity since 2012, through funding and support of novel collaborations and projects between artists and technologists or scientists, which in turn has impacted innovation in the tech sector across Europe. The impact includes demonstrating to the ICT/technology industry and the EC the value of artists in catalysing novel approaches to innovation. Over seven years, the initiative has resulted in over a hundred funded projects and in turn impacted hundreds of individual artists, ICT experts, and affiliated companies.

In this talk, I discuss not only the S+T+ARTS initiative and my role in it, but also how my practice and research led to this role, and new directions for $\mathrm{S}+\mathrm{T}+\mathrm{ARTS}$ and myself.

\section{A Brief history of STARTS $2012-2015$}

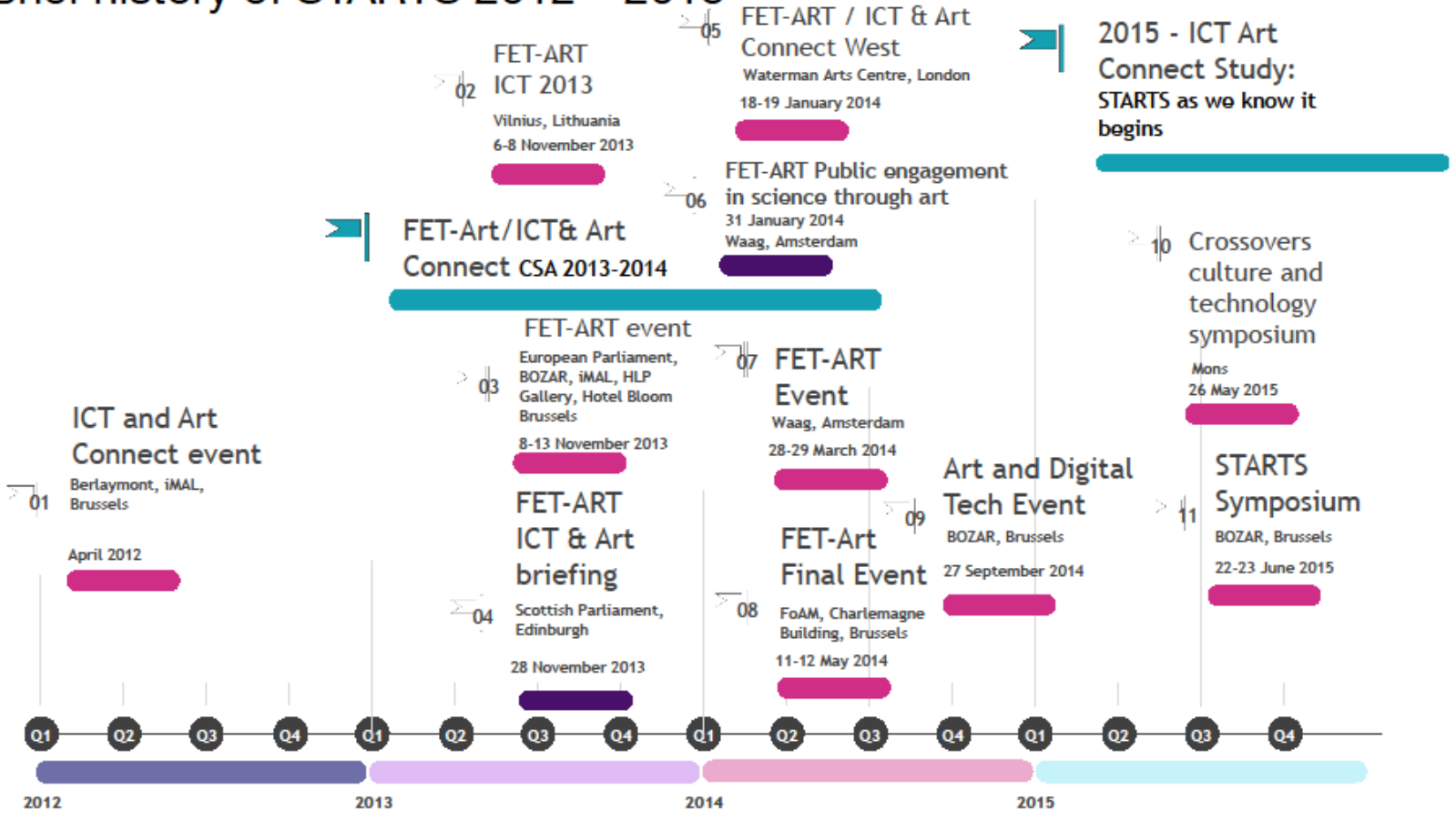

Figure 3: History of STARTS timeline (2012-2015). 


\section{Biography}

Camille Baker is an artist-performer/researcher/ curator within various art forms: participatory performance and interactive art, mobile media art, tech fashion/soft circuits/DIY electronics, responsive interfaces and environments, and emerging media curating. Baker develops methods and approaches to exploring the body within performance \& interactive art contexts, using etextiles, wearable technology, and mobile media. She is the Principal Investigator at the University for the Creative Arts for the EU-funded STARTS Ecosystem (http://starts.eu) April 2019 - November 2021 and founder initiator for the EU WEAR Sustain project January 2017 - April 2019 (http://wearsustain.eu). Her monograph New Directions in Mobile Media and Performance (Baker 2018) showcased exciting approaches and artists in this space, as well as her own work. The co-edited book of essays with Dr Kate Sicchio, Intersecting Art and Technology in Practice: Techne/Technique/ Technology (Baker \& Sicchio 2016), focused on the artistic process for those making work across art and technology tools. She is Professor of Interactive and Immersive Arts, in the School of Film, Media and Performing Arts at the University for the Creative Arts in Farnham, Surrey.

\section{Ghislaine Boddington}

University of Greenwich, UK

\section{The Internet of Bodies: The virtual physical blending of our bodies and our senses}

In 1999, I convened the symposium/workshop Virtual Physical Bodies (at Middlesex University, UK) to bring together a small group of international performing artists creating work using remote stage connectivity (telepresence) and interactive technologies. In this talk, with reference to my practice-led research background in the body and technology (1989-present) and my long-term research theme The Internet of Bodies (http://www.internetofbodies.net), I explore:

- the history of the connectivity of bodies through technologies;

- the present scenario, fast forwarded by the COVID19 lockdown pandemic requirements for near universal remote digital communication;

- the potential creative extensions (and issues) that are held within the future of connected bodies.

My work within creative interactive arts collectives shinkansen (1989-2004) and body>data>space (2004-present) has researched, through live installation and performative public experiences, the augmentation of the living body through digital technologies from the point of view of the living body as being central to such evolutions. This talk takes an overview of the gradual blending of our physical selves and our data selves, with references to artists, creative industries, and corporate developments in the last 40 years. It examines our shifting understanding of three key areas:

(i) our identities, which are diversifying, as they become hyper-enhanced and multi-sensory;

(ii) our collaborations, being enabled to deepen through co-operative connections traversing time and space;

(iii) our innovations, as the requirement to be collective, transforms our ability to diversify, encouraging inclusivity.

I propose that our bodies have finally become the interface and explore the positive and negative issues in this ongoing convergence, indicated by the advancement of virtual physical hybridity tools and platforms, the new environment/s of the future 'self'. The rapid growth of the digital literacy of the public, beyond the computer arts sector, and the issues of the ownership of our personal data will be outlined in relation to the changing definitions of identity and self-hood.

\section{Biography}

Ghislaine Boddington is Creative Director of body>data>space (http://www.bodydataspace.net) and Reader in Digital Immersion at the University of Greenwich. With a background in performing arts and body technologies, Ghislaine is recognised as a pioneer in the exploration of digital intimacy, telepresence, and virtual physical blending since the early 1990s. As a curator, keynote speaker, and radio presenter, she has shared her outlook on the future human into the cultural, academic, creative industries, and corporate sectors worldwide, examining topical issues with regards to personal data usage, connected bodies and collective embodiment. Her research led practice, examining the evolution of the body as the interface, is presented under the heading The Internet of Bodies (Boddington 2021).

Recent directions and curation outputs include "me and my shadow" (at the Royal National Theatre in 2012), FutureFest 2015-18 and Collective Reality (Nesta's FutureFest / SAT Montreal 2016/17). In 2017, Ghislaine was awarded the international IX Immersion Experience Visionary Pioneer Award. She recently co-founded the University of Greenwich Strategic Research Group, CLEI - Cocreating Liveness in Embodied Immersion, and is an Associate Editor for Al \& Society (published by Springer). Ghislaine is a long-term advocate for 
diversity and inclusion, working as a Trustee for Stemette Futures and Spokesperson for the Deutsche Bank We in Social Tech initiative. She is a team member and presenter with BBC World Service flagship radio show/podcast Digital Planet.

\section{Ernest Edmonds}

De Montfort University, UK

\section{AI, IA and Art}

Artificial Intelligence or Intelligence Augmentation? This talk is presented with reference to the Heron Island series of meetings on Computational Creativity that were held over the last 30 years on that Australian island. A central concern has been to take a human-centred perspective. This goes back to a research agenda that I first announced in a joint paper at a 1970 Computer Graphics conference: "The creative process where the artist is amplified or superseded by the computer". In recent years, there has been considerable progress in creative artificial intelligence applications and the talk considers the earlier arguments in the context of that progress, re-assessing them in the light of our understandings of today.

In my book with Margaret Boden (Boden \& Edmonds 2019), we spend time placing computational, $\mathrm{IA}$, and $\mathrm{Al}$ art in context, both philosophically and historically. One point from the book is the change in attitude and perception observable in different age groups. The talk draws this out from the interviews with artists included in that book. Today, we need to understand the creative thinking, the cognitive processes, of digital natives. The best approach that we have available for this must be based on creative reflective practice, where the creative practitioner themselves articulates the processes of their thinking. The talk concludes by revisiting the developments in $\mathrm{Al}$ as a component of my own art and by providing pointers into the future which, I argue, has more to gain from IA than Al.

\section{Biography}

Ernest Edmonds is an artist/researcher who, in 2017, received the ACM SIGGRAPH Distinguished Artist Award for Lifetime Achievement in Digital Art. Edmonds' skills are transdisciplinary. In 2017, he also won the SIGCHI Lifetime Achievement Award for the Practice of Computer Human Interaction. His most recent book was with Margaret Boden, From Fingers to Digits: An Artificial Aesthetic (Boden \& Edmonds 2019). He is currently Emeritus Professor at De Montfort University and Chair of the Board of ISEA International. His work was described in the book by Francesca Franco (2017), Generative Systems Art: The Work of Ernest Edmonds.

\section{CONCLUSION}

The five EVA London 2021 keynote talks were delivered online on each day of the conference from Monday to Friday, 5-9 July 2021.

Online information concerning the EVA London 2021 Conference is available under:

http://www.eva-london.org/eva-london-2021/

\section{BIBLIOGRAPHY}

Ascott, R. (1984) Art and Telematics: towards a network consciousness. Kunst und Telematik/L'Art et le Télématique. In $\mathrm{H}$. Grundmann (ed.), Art + Telecommunication. The Western Front, Vancouver.

Baker, C. (2018) New Directions in Mobile Media and Performance. Routledge.

Baker, C. and Sicchio, K. (eds.) (2016) Intersecting Art and Technology in Practice: Techne/Technique/ Technology. Routledge.

Boddington, G. (2000) Virtual presence physical beings - From telegraph to telecast. Middlesex University, UK.

Boddington, G. (2007) Virtual physical bodies Serious play. In H. Birringer, T. Dumke \& K. Nicolai (eds.), Die Welt als Virtuelles Environment, pp. 6492. Trans-Media-Akademie Hellerau.

Boddington, G. (2021) The Internet of Bodies Alive, connected and collective: the virtual physical future of our bodies and our senses. Al \& Society, Springer. DOI: 10.1007/s00146-020-01137-1

Boden, M. A. and Edmonds, E. A. (2019) From Fingers to Digits: An Artificial Aesthetic. MIT Press, Cambridge, MA.

Bowen, J. P. (2013) New art practice. In Bowen et al. (2013), Part II, pp. 73-74.

Bowen, J. P. (2020) A personal view of EVA London: Past, present, future. In Weinel et al. (2020), pp. 8-15. DOI: $10.14236 /$ ewic/EVA2020.2

Bowen, J. P. and Giannini, T. (2021) Digitality: A reality check. In Weinel et al. (2021), this volume.

Bowen, J. P., Giannini, T., Falconer, R., Magruder, M. T., and Marconi, E. (2021) Beyond Human: Arts and identity between reality and virtuality in a postCovid-19 world. In Weinel et al. (2021), this volume.

Bowen J. P., Keene, S., and Ng, K. (eds.) (2013) Electronic Visualisation in Arts and Culture. Springer, Series on Cultural Computing. DOI: 10.1007/978-1-4471-5406-8

Candy, L. (1992) Modelling the creative product versus supporting human creativity. AISB Quarterly, 81, pp. 31-34, Autumn. 
Candy, L. (2019) The Creative Reflective Practitioner: Research Through Making and Practice. Routledge, London.

Edmonds, E. (1993) Knowledge-based systems for creativity. In Gero \& Maher (1993), chapter 11, pp. 259-271.

Edmonds, E. and Franco, F. (2019) Evolving installations "Shaping Space". In Giannini \& Bowen (eds.) (2019a), chapter 18, pp. 367-379. DOI: 10.1007/978-3-319-97457-6 18

Fischer, G. (1993). Creativity enhancing design environments. In Gero \& Maher (1993), chapter 10, pp. 235-258.

Fish, J. and Scrivener, S. (1990) Amplifying the mind's eye: sketching and visual cognition. Leonardo, 23(1), pp. 117-126.

Franco, F. (2017) Generative Systems Art: The Work of Ernest Edmonds. Routledge.

Gero, J. S. and Maher, M. L. (eds.) (1993) Modeling Creativity and Knowledge-Based Creative Design. Lawrence Erlbaum Associates, Hillsdale, NJ. Republished by Psychology Press, 2016.

Gertzels, J. W. and Csikszentmihalyi, M. (1975) From problem solving to problem finding. In Taylor and Getzels (eds.), Perspectives in Creativity, Aldine Publishing Co., Chicago, IL.

Giannini, T. and Bowen, J. P. (eds.) (2019a) Museums and Digital Culture: New Perspectives and Research. Springer, Series on Cultural Computing. DOI: $10.1007 / 978-3-319-97457-6$

Giannini, T. and Bowen, J. P. (2019b) Digital culture. In Giannini \& Bowen (eds.) (2019a), chapter 1, pp. 3-26. DOI: 10.1007/978-3-31997457-6 1
Gill, S. P. (2015) Tacit Engagement: Beyond Interaction. Springer, Switzerland. DOI: 10.1007/978-3319-21620-1

Hemsley, J. (2013) The EVA London Conference 1990-2012: Personal reflections. In Bowen et al. (2013), pp. 1-5. DOI: $10.1007 / 978-1-4471-5406-$ 81

Markoff, J. (2015) Machines of Loving Grace: The Quest for Common Ground Between Humans and Robots. Ecco Press, Los Angeles, CA.

Masson T. (2007) CG101: A Computer Graphics Industry Reference, $2^{\text {nd }}$ edition. Digital Fauxtography.

Mitchell, W. J. (1993) A computational view of design creativity. In Gero \& Maher (1993), chapter 3, pp. 25-42.

Moore, P. V. (2019) The Quantified Self in Precarity: Work, Technology and What Counts. Routledge.

Schon, D. A. (1983) The Reflective Practitioner. Maurice Temple Smith, London.

Weinel, J., Bowen, J. P., Borda, A., and Diprose, G. (eds.) (2021) EVA London 2021: Electronic Visualisation and the Arts. BCS, Electronic Workshops in Computing (eWiC). ScienceOpen. DOI: 10.14236/ewic/EVA2021.0

Weinel, J., Bowen, J. P., Diprose, G., and Lambert, N. (eds.) (2020) EVA London 2020: Electronic Visualisation and the Arts. BCS, Electronic Workshops in Computing. ScienceOpen. DOI: 10.14236/ewic/EVA2020.0 